\title{
DISTRIBUTED HYDROGEN TECHNOLOGIES FOR COMMERCIAL BUILDINGS AND VEHICLE REFUELING
}

\section{ES2009-90008}

\author{
Ali A. Jalalzadeh-Azar \\ National Renewable Energy Laboratory \\ Golden, Colorado, 80401, U.S.A.
}

\begin{abstract}
This paper examines the potential energy, environmental, and economic benefits of hydrogen-based distributed generation (DG) systems with dual application-commercial buildings and vehicle refueling. The selected DG systems incorporate fuel cell technologies for power generation and natural gas reformation for hydrogen production. In addition to basic systems, more advanced configurations facilitating heat recovery for the reformer and the building heating equipment are considered. Integration of stationary and transportation applications within the context of a commercial community is also explored on the premise of utilizing a joint hydrogen production facility for cost reduction.
\end{abstract}

While appreciable improvement in greenhouse gas (GHG) emissions is evidently intrinsic to all selected stationary DG models, a significant reduction in the primary energy use is achieved with the more-advanced systems, particularly the one with internal heat recovery. A negligible impact on the water consumption is registered when water management is in place for the fuel cell systems. The integration strategy highlighting the community buildings as the surrogate supplier of hydrogen for vehicle refueling is more tenable from the economic standpoint than the reversed arrangement.

\section{INTRODUCTION}

Diversity in the energy-technologies portfolio is an important facet of the energy market competitiveness and is critical to optimum management of the energy resources within the economic and environmental confines. Introducing hydrogen technologies to stationary applications (such as commercial buildings) offers a technological diversity to the sector responsible for one-third of the U.S. energy consumption. ${ }^{1}$ Including the transportation, the potential operating domain of such technologies encompasses a much greater portion of the market with an energy demand comprising about two-thirds of the total. These notions point to the magnitude of the potential contributions hydrogen technologies can make in addressing the energy and environmental issues.

At the macro level, successful large-scale implementation of hydrogen technologies requires well-planned infrastructure, central and/or distributed, for production and delivery of hydrogen. Equally important is the micro-level attention to hydrogen utilization effectiveness and efficiency of the end-use systems that will collectively influence the potential economic and environmental benefits of such technologies and, consequently, their market acceptance. Compared with transportation, the dynamics on the stationary demand side involve a different set of complexities arising from the wide spectrums of the building functions and systems. Although the stationary fuel cell systems, the best candidates for on-site utilization of hydrogen, are in principle similar to those of the fuel cell vehicles (FCV), they are vastly different in functionality due to their physical and operational integration with the building end-use equipment. These complexities necessitate comprehensive analyses for (1) screening the available alternatives for efficient utilization of hydrogen in buildings and (2) exploring the potential for synergistic integration of stationary and transportation applications. The findings and insight to be gained from such analyses can feed into macro-level evaluation of the energy supply/demand dynamics that is central to characterization and projection of the future infrastructural needs.

Market acceptance of hydrogen technologies for either of the two applications (i.e., stationary or transportation) depends on meeting technical targets and deployment policies, all of which contribute to uncertainties in projecting the future market share. In a study [1], three scenarios for market penetration of FCV 
were considered for early market transition. The most aggressive scenario considered 10 million hydrogen vehicles on the road and 8,000 refueling stations in metropolitan areas by 2025. It is perceivable that a parallel market penetration of hydrogen technologies for buildings will further accelerate this market transition through cost sharing of infrastructure development for hydrogen production, distribution, and delivery. For synergistic integration of stationary and transportation applications, this study focuses on the decentralized hydrogen production technology.

The key objectives of this study are:

1. Perform energy analysis for the most prevalent commercial-building types under different DG scenarios.

2. Assess the requirements for the energy and water resources for the selected DG hydrogen technologies.

3. Evaluate the potential of tri-generation configurations that meet the electrical and thermal loads of commercialbuilding communities and supply hydrogen to on- or nearsite vehicle refueling facilities-integrating stationary and transportation applications.

4. Address the potential energy, economic, and environmental benefits of the tri-generation concept.

In exploring the stationary/transportation concept, two models are examined-Model I and II. In Model I, the constituent buildings take the center stage but share their domain with the vehicle refueling station within a commercial community. The hydrogen production system is characterized and specified to meet the design electrical load of the stationary fuel cell systems serving the buildings. The production system is, however, allowed to operate continuously to facilitate excess hydrogen production and storage during the off-peak periods for vehicle refueling. As evidenced from this characterization, the refueling capacity of the participating station is collectively dictated by the energy load profiles of the buildings. The second integration model (Model II) meets hydrogen demand of commercial buildings (for on-site power generation) with an oversized hydrogen production facility that is primarily dedicated to the vehicle refueling station operating within the commercial community. With this integration scheme, the transportation application takes precedence. In line with the H2A model [2], the baseline capacity of the refueling station in Model II is taken to be $1,500 \mathrm{~kg}$ of hydrogen per day.

For the resource assessment focusing on the commercial buildings, the analysis considers various hydrogen-fueled distributed generation (DG) systems for selected commercial buildings, representing the broader building categories defined by the DOE/Energy Information Administration ${ }^{1}$ (EIA). The analysis also covers different types of fuel cell technologies

\footnotetext{
${ }^{1}$ http://www.eia.doe.gov/emeu/cbecs/building_types.html
}

that are allowed to operate in a stand-alone mode and in the context of combined heat and power (CHP). The CHP system is an electrical-load-following model configured to utilize the heat output of the fuel cells for space and service hot-water heating. Any thermal energy demand in excess of the available heat output is met by gas-fired burners/furnaces.

Previous studies [3 and 4] have demonstrated that the influence of the DG system electrical efficiency on the overall CHP performance is more pronounced than that of the thermally activated (TA) equipment. Those studies focused on the performance of micro-turbines. However, the findings of the current study, which incorporates fuel cell technologies, basically echo those of the previous (as will be discussed later).

The types of commercial buildings addressed here for the resource assessment are offices, hospitals, high schools, restaurants, supermarkets, and retail stores. These, respectively, belong to the following EIA-defined categories: office, inpatient health care, education, food service, and retail. At the national level, the combined energy consumption of these buildings represents roughly $70 \%$ of the aggregate of all commercial buildings [5]. On the other hand, the building-type selection for the tri-generation concept integrating stationary and transportation applications is less diverse and focuses on communities consisting of offices, hospitals, retail stores, and supermarkets. In defining this commercial community, the EIA data were used to quantify the composition of the four building types.

\subsection{System Description}

As illustrated in Figure 1, the DG system conceptualized for this analysis consists of two major sub-systems: a hydrogen production unit and a fuel cell. For production, natural gas reformation (natural gas reformation) is considered. The production unit is aligned with a low-temperature proton exchange membrane, phosphoric acid, or solid oxide fuel cell, which are referred to as PEMFC, PAFC, and SOFC, respectively, hereafter. The fuel cell-based distributed generation systems of this study are conceptualized in Figure 2 and described below.

- At the simplest form, the fuel cell systems operate without any heat recovery, forming the most basic DG system of analysis-FCDG. In the absence of heat recovery, either of the three fuel-cell types is used to generate only electricity.

- A more advanced system, FCDG-ADV, is also characterized for the case incorporating SOFC. In this scenario, the reformer is more efficient than that of FCDG and utilizes the available high-grade heat from the fuel cell stack to offset a significant portion of its combustionfuel requirement. 


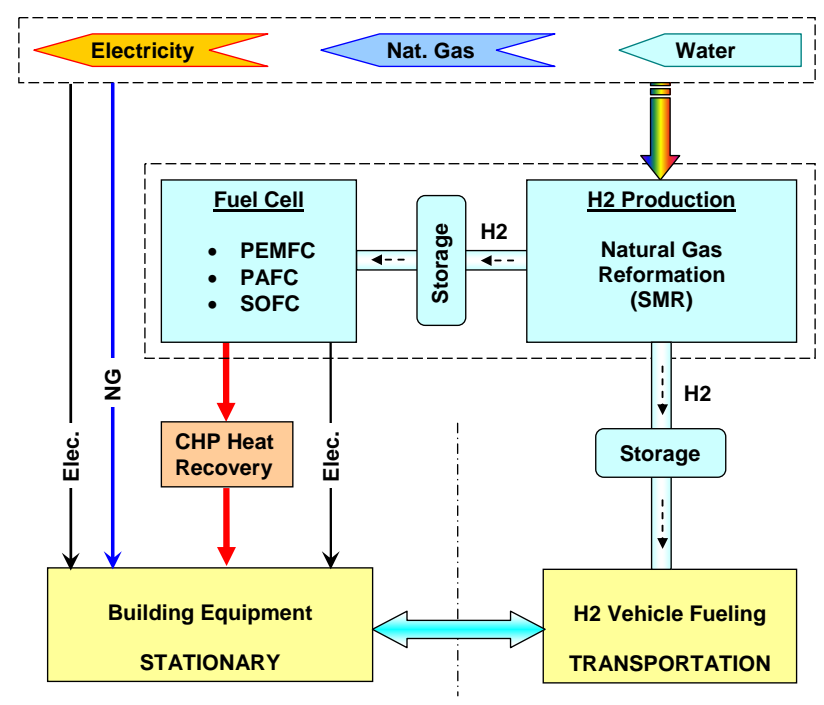

Figure 1. Schematic of conceptualized distributed system
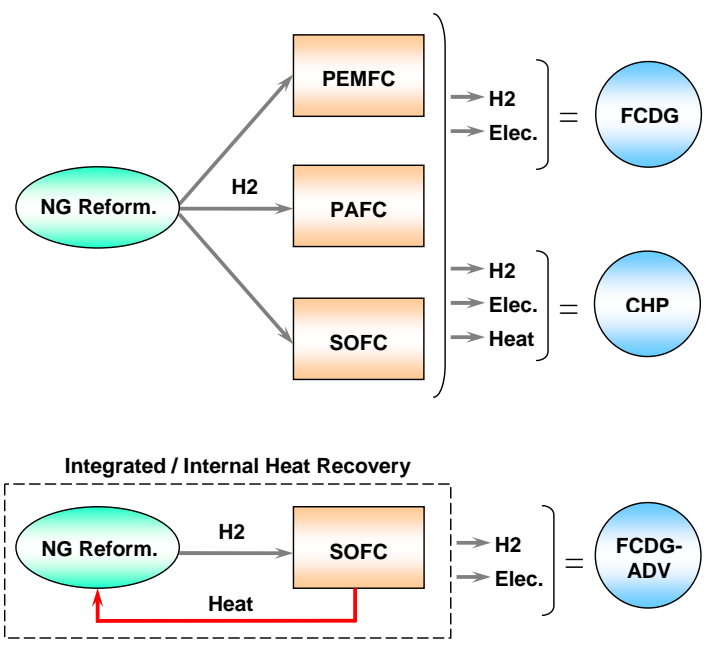

Figure 2. Conceptualized alternative DG configurations

- The third scenario is an electrical-load-following CHP system that facilitates heat recovery from the fuel cells for the building equipment-the space heating system and/or service hot-water heater. While these heating devices are retrofitted to operate as TA systems, the electric space cooling equipment of the building served by the DG system remains intact.

- In the analysis, the three hydrogen-based DG systems are specified to meet the entire building electrical load and, therefore, are grid-independent.
In reference to the temperature compatibility criterion, only PAFC and SOFC can support both space and service hot-water heating systems in the CHP scenario. The low-temperature PEMFC is only suitable for service hot-water heating and, as a result, its heat recovery potential is limited in some commercial building types, such as "office.” For each building category, these hydrogen-based alternative systems are evaluated in reference to a conventional baseline system that utilizes grid electricity and natural gas to meet the electrical and thermal loads of the building. All three scenarios-FCDG, FCDG$\mathrm{ADV}$, and $\mathrm{CHP}$ — can lend themselves to vehicle refueling.

The concept of a tri-generation system serving commercial buildings and a vehicle refueling station within a community is illustrated in Figure 3. The commercial community incorporates a single production facility to meet the hydrogen requirements of the stationary (buildings) and transportation (vehicle refueling) applications under the two prescribed integration models.

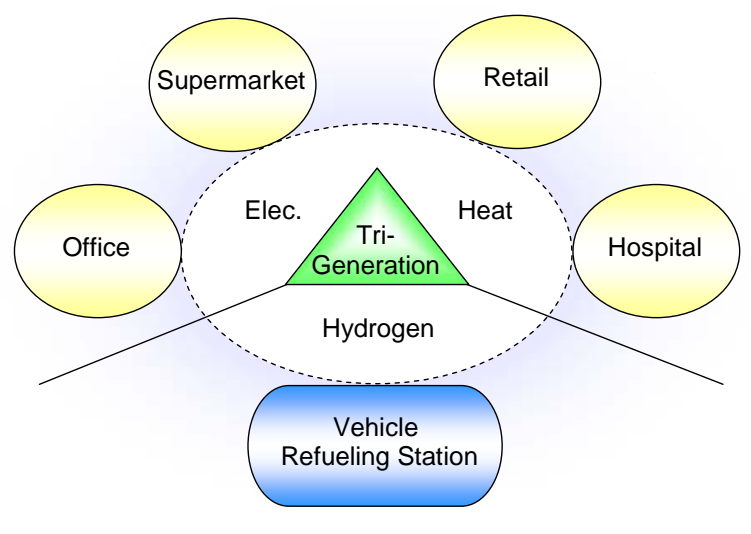

Figure 3. Tri-generation system serving a community of buildings and a refueling station

\section{Method of Analysis}

\subsection{Efficiency Evaluation}

The hydrogen production efficiency of the natural gas reformation is obtained from the H2A Production model [2]. The electrical efficiency of each fuel cell type is assumed to be constant and independent of the upstream production process. The fuel cell efficiencies are determined based on a literature review [6-9]. For a given fuel cell system, the power output is calculated from the following expression:

$$
\dot{E}_{F C}=\eta_{F C} \cdot \dot{m}_{H_{2}} \cdot L H V_{H_{2}}
$$

The overall electrical efficiency of a hydrogen-based DG system accounting for both hydrogen production and fuel cell 
power generation is then determined by multiplying the efficiencies of the fuel cell system and production unit.

\section{$2.2 \quad$ Heat Recovery}

In modeling the heat recovery process in the CHP system, the TA systems are cascaded in a manner to allow maximum possible heat utilization by prioritizing the active systems in accordance with their operating temperatures. The exhaust thermal energy of each TA system is combined with the unused portion of the main heat stream to energize the downstream TA device.

The maximum specific thermal output of a fuel cell available for the heat-driven systems is expressed in terms of $\mathrm{kWh}$ of heat per kWh of electrical energy output:

$q_{\max }=\frac{\dot{Q}_{\max }}{\dot{E}_{F C}}=\gamma\left(\frac{1}{\eta_{F C}}-1\right)$

where $\gamma$ is a less-than-unity coefficient that accounts for the unrecoverable thermal energy losses, such as radiation. The maximum specific heat transferrable to a given TA system $\left(q_{\text {TAi }}\right)$, expressed in terms of $\mathrm{kWh}$ per $\mathrm{kWh}$ of electrical energy output of the fuel cell in operation, is determined from

$q_{T A i}=R_{T A i}\left(\frac{\dot{Q}_{\text {avail } T A i}}{\dot{E}_{F C}}\right)=\left(\frac{T_{S, T A i}-T_{T A i}}{T_{S, T A i}-T_{\text {ref }}}\right)\left(q_{\max }-\sum_{m=1}^{i-1} c_{m} q_{T A m}\right)$

The variable $R_{\text {TAi }}$ is the heat utilization factor for TA device $i$, which is a function of the source temperature available for the TA system $\left(T_{S, T A i}\right)$ and the system operating temperature $\left(T_{\text {TAi }}\right.$ ). The subscript $m$ denotes the upstream TA devices. The coefficient $C_{m}$ in Equation 3 is zero if the corresponding TA device $m$ is not activated, less than unity if the required heat is less than the available heat, and unity if the required heat is equal or greater. A negative value of $q_{T A i}$ reflects the amount of thermal energy to be offset by natural gas. The effective temperature of the heat source along the main stream (Figure 2) is estimated as a function of a conceptual bypass factor $(\alpha)$ and the source temperature for the upstream TA system:

$T_{S, T A i}=\left[\alpha T_{S}+(1-\alpha) T_{S}\right]_{T A(i-1)}$

where $\alpha$ is equal to $\left(\dot{Q}_{\text {avail,TA }(i-1)}-\dot{Q}_{\text {req,TA(i-1) }}\right) /\left(\dot{Q}_{\text {avail,TA }(i-1)}\right)$ if $\dot{Q}_{\text {avail,TA(i-1)}}>\dot{Q}_{\text {req,TA(i-1) }}$ and zero otherwise. The above formulation is general and can accommodate TA absorption cooling systems as well. The actual heat transfer to a given TA system is the product of $q_{T A i}$ (Equation 3) and the effectiveness of the system heat exchanger interfacing with the heat stream.

\subsection{Energy Impact}

The impact of implementing a given alternative (FCDG, FCDG-ADV, or CHP) on the electricity requirement at the national level is estimated based on the EIA data. The change in the annual electrical energy consumption is estimated as

$\Delta E_{\text {Total Elec. }}=p \sum_{b=1}^{B} \sum_{l=1}^{L} \frac{\left(\delta_{\text {Elec }, b, l}\right)_{\text {Alt. }}}{\left(E_{\text {Elec }, b, l}\right)_{\text {Baseline }}}\left(E_{\text {Elec, }, b}\right) / N_{l}$

In this equation, $p$ represents the fraction of the commercial market adopting a hydrogen-based alternative, and $\delta$ is the change in the annual electricity use relative to the electricity load of the benchmark (baseline) building. The subscripts $b$ and $l$ denote the building type and location, respectively. The upper limit $B$ is the total number of building types, and $N_{l}$ is the number of locations representing various climates.

The corresponding primary (source) energy use was calculated based on an overall electrical efficiency of 0.33 for the central power plants. The expression for estimating the annual natural gas consumption is similar to Equation 5.

\subsection{Economic Impact}

The potential cost savings stemming from use of a single hydrogen production facility for the community buildings and vehicle refueling station in Model II is evaluated as

$$
\Delta C=C_{\text {Baseline }}\left[\left(2-S R_{\text {Oversized }}\right)^{S F}-\left(S R_{\text {Oversized }}\right)^{S F}\right]
$$

In this equation, $\Delta C$ is the cost savings; $C_{\text {Baseline }}$ is the baseline cost of the production system (obtained from the H2A case studies for a production capacity of 1,500 $\mathrm{kg} /$ day); $S R_{\text {Oversized }}$ is the scaling ratio for an oversized production system ( $S R_{\text {Oversized }}>1$ ); and $S F$ is the scaling factor exponent. Equation 6 basically determines the savings as the difference between the displaced cost of an additional production facility required for buildings and the incremental cost associated with oversizing the transportation-designated production system for the dual application.

\subsection{Building Load Profiles}

For analysis of the building energy (electricity and natural gas) and water consumption, the hourly building load profiles were represented by the DOE Commercial Building Research Benchmark [10]. (The benchmark methodology and profiles are currently under review and subject to revision in the future.) The benchmark data applied in this study are for new constructions incorporating conventional systems that are fully 
described in the 2004 ASHRAE Standard 90.1 [11]. In this study, the benchmark building equipment is referred to as the "baseline" system.

\subsection{Assumptions}

In line with the scope and objectives of this study, the following simplifying assumptions are made:

- Any waste heat recovery from the exothermic reactions in the production process is used within that unit for production efficiency improvement, which is not explicitly addressed here.

- Water recovery from the fuel cell stack offsets part of the water required for hydrogen production.

- Due to the availability of only hourly building load profiles, the time increment applied for computations is one hour, and the effect of energy-demand fluctuations within that time period is neglected.

- The effects of transient behavior, response time, and startup time of the equipment, including the fuel cell systems, are not considered.

- The average performance data for the equipment are applied to the yearly energy simulations across the entire spectrum of the operating conditions.

The results of the analysis presented in this report are based on the assumptions for the key distributed systems, as provided in Table1. Other pertinent assumptions are:

- Considering that the actual water requirement in the steam methane reformers is three parts of steam per part of fuel [9] compared to the theoretical ratio of two, the excess water input is basically assumed to be discarded without any recovery. The natural gas reformer is assumed to be air-cooled and does not require make-up water for cooling.

- The net water recovery from the fuel cell stacks is at $70 \%$.

- The minimum unrecoverable heat losses of fuel cell systems comprise $8 \%$ of the hydrogen energy input.

- The effectiveness of the heat exchanger used for heat recovery is 0.75 .

On the transportation side, in accordance with the assumptions made in the 2006 Posture Plan [12], the following performance metrics are applied.

- The average hydrogen vehicle is driven about 13,000 miles/year.

- FCVs are rated at 50 miles/kg hydrogen.

The $\mathrm{CO}_{2}$-equivalent emission rates used in this study are based on those of the H2A model [2].
Table 1. Key assumptions

\begin{tabular}{|c|c|c|c|c|}
\hline 量 & 岂 & ت⿹ & 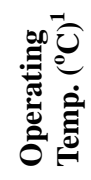 & 氮 \\
\hline $\begin{array}{l}\text { Distributed } \\
\text { Hydrogen } \\
\text { Production }\end{array}$ & $\begin{array}{l}\text { NG } \\
\text { Reformer }\end{array}$ & 0.75 & N/A & $\begin{array}{l}\text { FCDG, } \\
\text { FCDG-ADV, } \\
\text { and CHP }\end{array}$ \\
\hline \multirow{3}{*}{$\begin{array}{l}\text { Distributed } \\
\text { Power } \\
\text { Generation }\end{array}$} & PEMFC & 0.42 & 90 & FCDG \\
\hline & PAFC & 0.48 & 190 & $\begin{array}{l}\text { FCDG and } \\
\text { CHP }\end{array}$ \\
\hline & SOFC & 0.56 & 600 & $\begin{array}{l}\text { FCDG, } \\
\text { FCDG-ADV, } \\
\text { and CHP }\end{array}$ \\
\hline \multirow{3}{*}{$\begin{array}{l}\text { End-Use } \\
\text { Systems }\end{array}$} & $\begin{array}{l}\text { Electric } \\
\text { Cooling }\end{array}$ & $\begin{array}{l}3.0 \\
\text { COP }\end{array}$ & N/A & $\begin{array}{l}\text { Baseline, } \\
\text { FCDG, } \\
\text { FCDG-ADV, } \\
\text { and CHP }\end{array}$ \\
\hline & $\begin{array}{l}\text { Gas-fired } \\
\text { Furnace/ } \\
\text { Space } \\
\text { Heating }^{2}\end{array}$ & $\begin{array}{l}0.80 \\
\text { AFUE }\end{array}$ & 80 & $\begin{array}{l}\text { Baseline, } \\
\text { FCDG, } \\
\text { FCDG-ADV, } \\
\text { and CHP }\end{array}$ \\
\hline & $\begin{array}{l}\text { Gas-fired } \\
\text { Service } \\
\text { Hot-Water } \\
\text { Heater }^{2} \\
\end{array}$ & $\begin{array}{l}0.62 \\
\text { AFUE }\end{array}$ & 50 & $\begin{array}{l}\text { Baseline, } \\
\text { FCDG, } \\
\text { FCDG-ADV, } \\
\text { and CHP }\end{array}$ \\
\hline \multicolumn{5}{|c|}{$\begin{array}{l}\text { 1. Nominal values } \\
\text { 2. Gas-fired systems retrofitted for adaption to non-combustion } \\
\text { heat source in the CHP case }\end{array}$} \\
\hline
\end{tabular}

\section{$3 \quad$ Results and Discussions}

\subsection{Baseline System}

The building systems of the benchmark profiles represent the baseline systems applied in this study. These systems entirely rely on electric grid for their electrical energy loads. The locations of the benchmark buildings virtually represent all U.S. climates.

Figure 4 presents the relative contribution of each of the selected EIA building types to the total electricity and natural gas consumptions of all EIA-aggregated commercial buildings. Referring to this figure, for both electricity and gas, the energy consumption for the combination of the selected buildings is about $65 \%$ of the total for all commercial buildings. From the standpoint of electrical energy consumption, the "office" is the most dominant component, followed by "education." These two building types also make up a greater share of the total natural gas usage in the commercial sector. The ratio of the primary energy requirement for generation of the required site electricity to the corresponding natural gas consumption is also 
plotted in Figure 4. The dominance of the electricity-related primary energy consumption in comparison with natural gas for office buildings is well pronounced. On average, such primary energy is about 5.5 times that of the natural gas for the selected buildings.

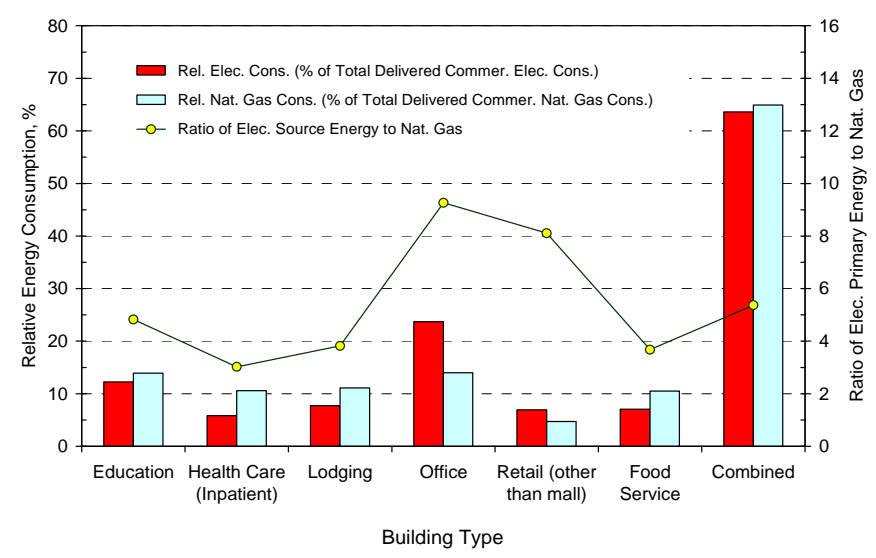

Figure 4. Relative energy use of various building typesEIA data

\subsection{Resource Assessment}

To determine the collective impact of hydrogen-based DG technologies on the energy requirements at the national level, the selected alternatives were analyzed for each benchmark building, and the results were extrapolated using the EIA data for commercial buildings. Equation 5 was used to estimate such impacts. For the resource assessment, the following assumptions are made.

- $\quad$ Each alternative (FCDG, FCDG-ADV, or CHP) is treated independently as if it is the only market choice other than the conventional (baseline) scenario.

- Any given alternative is assumed to capture only $20 \%$ of the existing market share of the selected commercial buildings (education, inpatient health care, lodging, office, retail, and food sale/service).

- The market shares of the three fuel cell technologies (i.e., PEMFC, PAFC, and SOFC) are equal for scenario FCDG. (By definition, only SOFC is used in scenario FCDG-ADV.)

- The CHP system provides heat for space and hot water heating. Therefore, PEMFC is not included in the assessment because its low-grade heat is insufficient to operate the space heating system, and its use for hot-water heating offers a limited advantage, as discussed earlier. The market shares of PAFC and SOFC are equal in the CHP scenario.

Figure 5 reflects the changes in the annual electricity and natural gas consumptions resulting from implementation of each of the three alternatives under the above assumptions. Figure 6 shows the same results for the two forms of the delivered energy in percentages of the corresponding total energy use in the commercial sector reported by EIA. Figure 6 indicates that about $16 \%$ of the total grid-electricity use can be saved by either of the alternatives. Alternative FCDG-ADV requires about $29 \%$ more natural gas compared to $49 \%$ and $43 \%$ for FCDG and CHP, respectively.

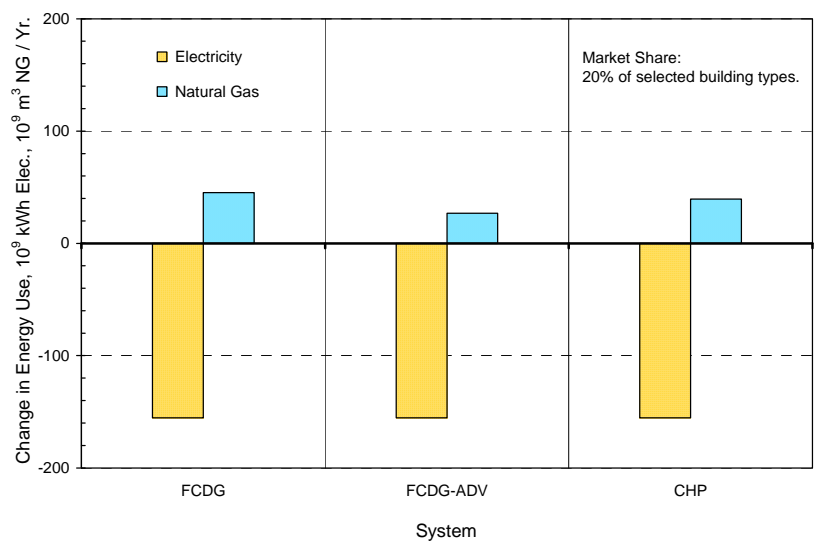

Figure 5. Impact of alternatives on energy use with $20 \%$ of commercial market share

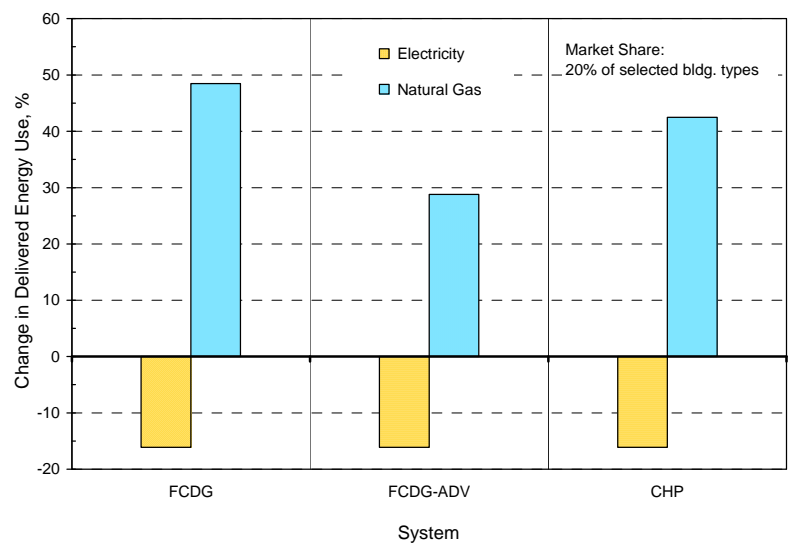

Figure 6. Relative Change in energy use for alternatives with $20 \%$ of commercial market share

\subsection{Stationary / Transportation Integration}

Without oversizing the distributed hydrogen production system designated for the buildings, its potential contribution to vehicle refueling was examined (Model I). In doing so, the system was allowed to operate continuously to produce hydrogen and dispense the excess amount resulting from the off-peak operations for vehicles. Figure 7 provides the hydrogen fueling capacities for the benchmark office and hospital in the selected locations for the three fuel cell 
systems-PEMFC, PAFC, and SOFC. (Note that the amount of hydrogen required to meet the building electrical load is independent of the hydrogen production pathway and is dictated by the fuel cell efficiency only.) The normalized results in Figure 7 show the number of vehicles that can be refueled solely by the excess on-site hydrogen production per GWh of the building's annual electrical load. The bar charts depict the percentage of the office occupants who could rely on the on-site hydrogen production should they own FCVs. The bar charts are based on a uniform occupancy of $25 \mathrm{~m}^{2}$ per person for the benchmark office [10, 11]. The refueling capacity of the stationary system was determined based on the previously stated assumptions that the average hydrogen vehicle is driven about 13,000 miles/year with a fuel economy of 50 miles/kg hydrogen. (Similar results are not provided for the benchmark hospital because the occupancy rate significantly varies with the zone functionality within the building.). The results of Figure 7 are based on a floor area of $10,000 \mathrm{~m}^{2}$.

For these estimates, the hydrogen production unit is assumed to operate continuously at a constant capacity commensurate with the $95 \%$ of the maximum peak electrical load. Therefore, with this assumption, the excess hydrogen production decreases with the increasing efficiency of the operating fuel cell system. As a result, SOFC yields the lowest refueling capacity (Figure 7). However, the trend would be reversed if the production capacity is fixed regardless of the fuel cell type. In line with the earlier characterization (Figure 2), the results shown for SOFC are applicable to FCDG, FCDG-ADV, and CHP, whereas the results for PEMFC are valid for FCDG only.

Figure 8 presents the significance of each building type within the EIA-based reference commercial community in providing hydrogen for FCVs in three selected locations. The refueling capacities shown in this figure are estimated per $10,000 \mathrm{~m}^{2}$ of the aggregated floor area of the constituent building typeshospital, retail, office, and supermarket-assuming PEMFC is used. For a given location, the contribution of "office" to the hydrogen supply for refueling is much greater than those of the other building types. Therefore, office buildings can potentially capture a much greater share of the market due to their stronger presence among the commercial buildings, as suggested by the EIA data. In Figure 9, the combined fueling capacity of these buildings is presented for two fuel cell types (PEMFC and SOFC) in the selected locations. A seemingly contradictory notion is the less-pronounced excess hydrogen production (for transportation) with the case of SOFC. However, by assumption, the hydrogen production system is prescribed to meet the design electrical loads of the building and, hence, the fuel cell system. Therefore, the more-efficient fuel cell requires a smaller production unit, reducing the potential for excess hydrogen during off-peak periods.

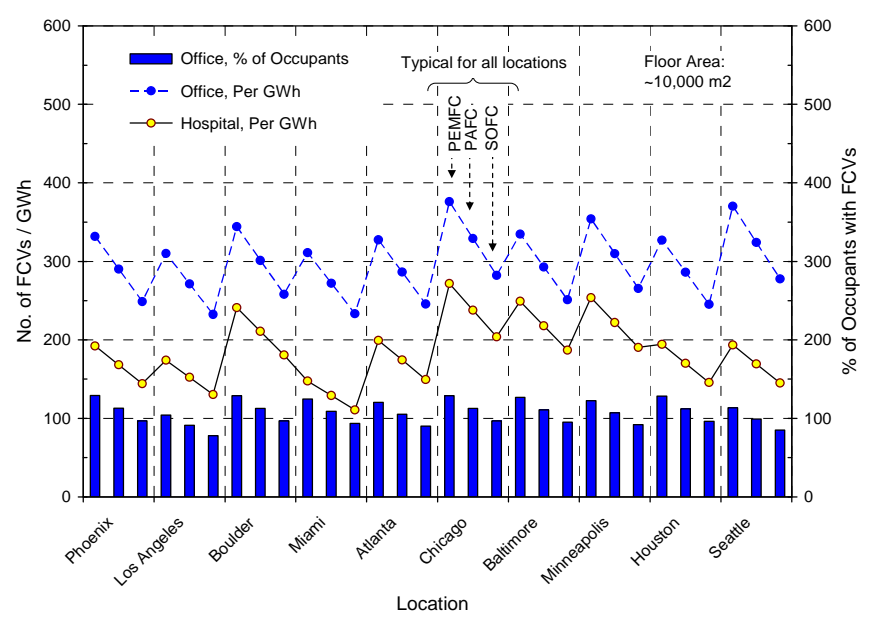

Figure 7. Normalized vehicle fueling capacity for two building types-office and hospital

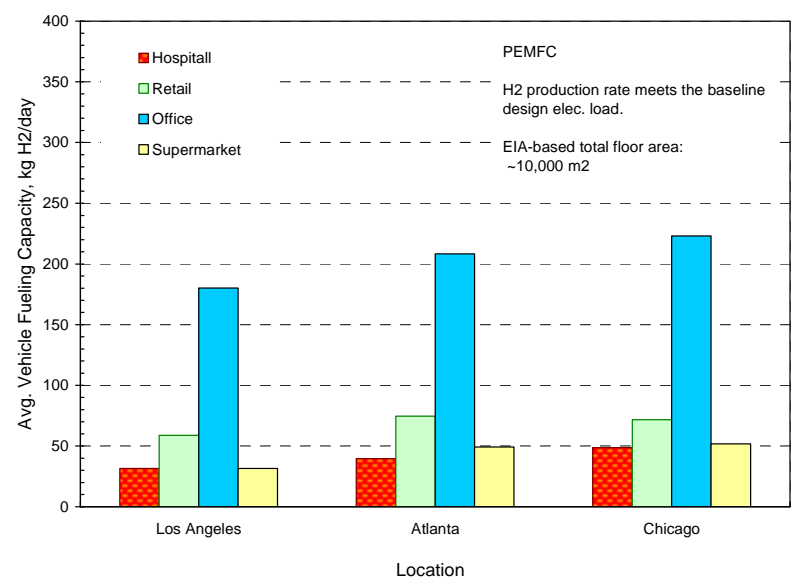

Figure 8 Vehicle refueling supported by buildings-Model I

An appreciable climatic impact on vehicle fueling potential is observed in Figures 8 and 9. The impact can be attributed to the variation in the frequency distribution of the building electrical load, which is influenced in part by the climate-dependent cooling load. Based on Figure 9, a group of commercial buildings with a total floor area of $50,000 \mathrm{~m}^{2}$, can support a nearby hydrogen fueling station with an average capacity of up to about $1,500 \mathrm{~kg}$ of hydrogen per day in Los Angeles and about 2,000 kg/day in Chicago.

Figure 10 quantifies the potential of the hydrogen production system of the community refueling station in supporting the fuel cell systems of the buildings (Model II integration). The total aggregated floor area of the community building that can be supported in this integration model is shown as a function of 


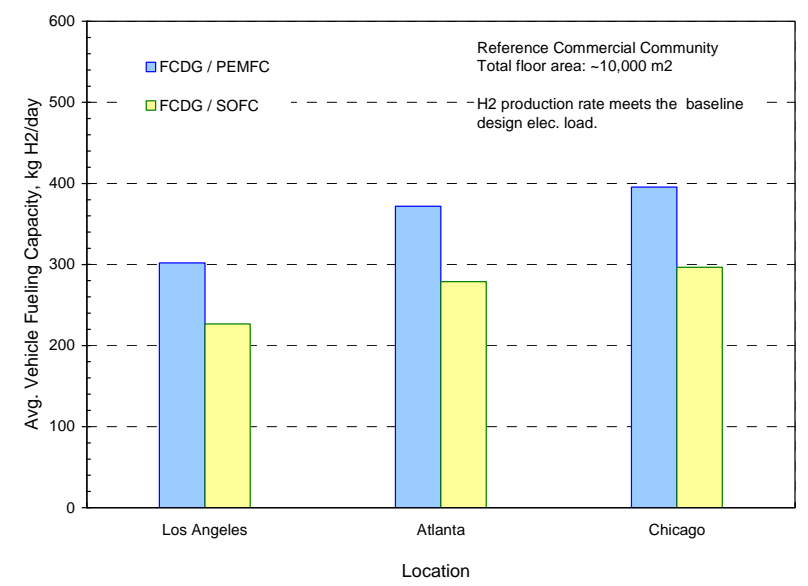

Figure 9. Potential of EIA-based commercial community for vehicle refueling-Model I

the refueling capacity increase. The impact of the efficiency of the stationary fuel cell system is also addressed in this figure by considering PEMFC and SOFC for the buildings. Due to its higher electrical efficiency, SOFC supports a larger EIAaggregated floor area of the community buildings. For example, oversizing the production system by $60 \%$ meets the hydrogen requirement of about $30,000 \mathrm{~m}^{2}$ of the buildings with PEMFC compared to approximately $40,000 \mathrm{~m}^{2}$ for the case with SOFC. Stated differently, for a given floor-area coverage, the required excess capacity for the case of PEMFC is greater than that for SOFC. Referring to Figure 10, for 30,000 $\mathrm{m}^{2}$, using SOFC in lieu of PEMFC reduces the supplementalcapacity requirement from about $60 \%$ to approximately $42 \%$. To support the $50,000-\mathrm{m}^{2}$ building community of the previous example for Model I, the refueling station capacity has to be doubled when PEMFC is used.

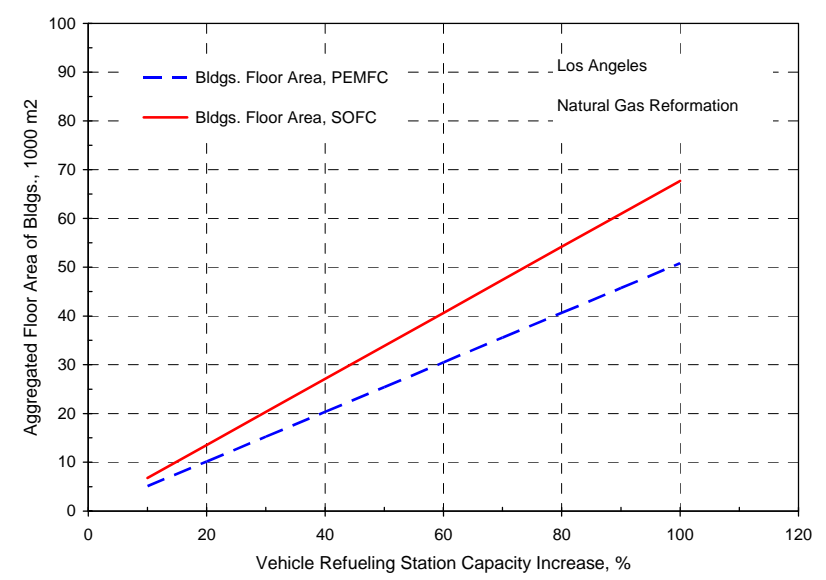

Figure 10. Potential of stationary/transportation integration-Model II

\subsection{Primary Energy and GHG Emissions}

Figure 11 examines the impact of the three alternative systems (FCDG, FCDG-ADV, and CHP) on primary energy consumption and GHG emissions of the commercial buildings. Outside the context of stationary/transportation integration, the hydrogen production rate in this analysis is not kept constant and varies with the electricity demand of the buildings. The analysis assumes that any given alternative captures only $20 \%$ of the commercial market consisting of the building types in Figure 4-offices, supermarkets, retail stores, hospitals, schools, and hotels. Of the three alternatives, FCDG-ADV is the most advantageous system in terms of primary energy use and GHG emissions followed by the CHP system (Figure 11). The alternative FCDG-ADV reduces the primary energy consumption by approximately $8.5 \%$ and abates $11.5 \%$ of the GHG emissions.

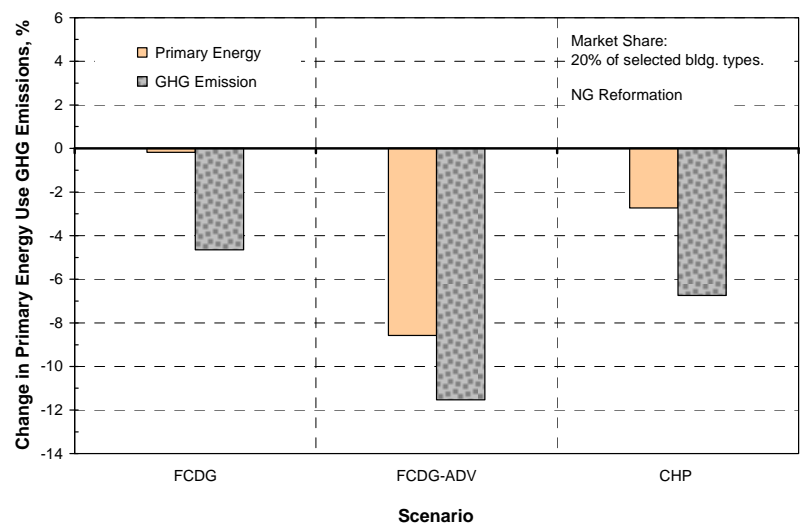

Figure 11. Impact of stationary systems on primary energy consumption and emissions at $20 \%$ market share

\subsection{Economic Impact}

For integration Model I, Figure 9 implies that a 50,000-m² EIA-aggregated commercial community in Los Angeles can potentially meet the hydrogen demand of a $1,500-\mathrm{kg} / \mathrm{day}$ vehicle refueling station, provided that the stationary hydrogen production facility is sized for PEMFC operation. (A smaller building community is needed in Atlanta and Chicago, as the excess-hydrogen production capacity per unit floor area is higher in those locations.) Therefore, installation of an equivalent production system for a refueling station can be avoided, saving up to about $\$ 1 \mathrm{M}$ in capital cost (based on the H2A case study for steam methane reformation [2]). Although the costs of accessories, such as storage and compressors, are not addressed here, they incur with or without the integration concept. However, the cost of piping for transporting the hydrogen from the production site to the refueling station for Model I is not necessarily the same as that for a case where independent production facilities are deployed. The piping cost and the related indirect expenses (e.g., permit) have to be taken into account in detailed economic analyses. 
Figure 12 presents the results of an economic assessment with the Model II integration where the excess hydrogen from the refueling station supports the building application. These results are based on Figure 10, which quantifies the extent to which oversizing the production capacity of the fueling station can potentially support the building community. Equation 6 is used to estimate the potential savings reported in Figure 12. The equation is assumed to be valid for the scaling ratio between $30 \%$ and $70 \%$. Two values of 0.6 and 0.8 are considered for the scaling factor $S F$ to demonstrate its impact. The net cost reduction improves with the decreasing scaling factor and with the decreasing production capacity increase, as suggested by Figure 12 .

Referring to Figure 10, a $60 \%$ increase in the capacity of the participating refueling station in Los Angeles can support a $30,000-\mathrm{m}^{2}$ commercial-building community that adopts PEMFC. Therefore, the potential cost reduction is approximately $\$ 0.5 \mathrm{M}$ based on the scaling factor of 0.6 (Figure 12). The savings would be roughly halved if the scaling factor is assumed to be 0.8 . The earlier discussions made under Model I regarding the accessory costs are equally applicable to Model II.

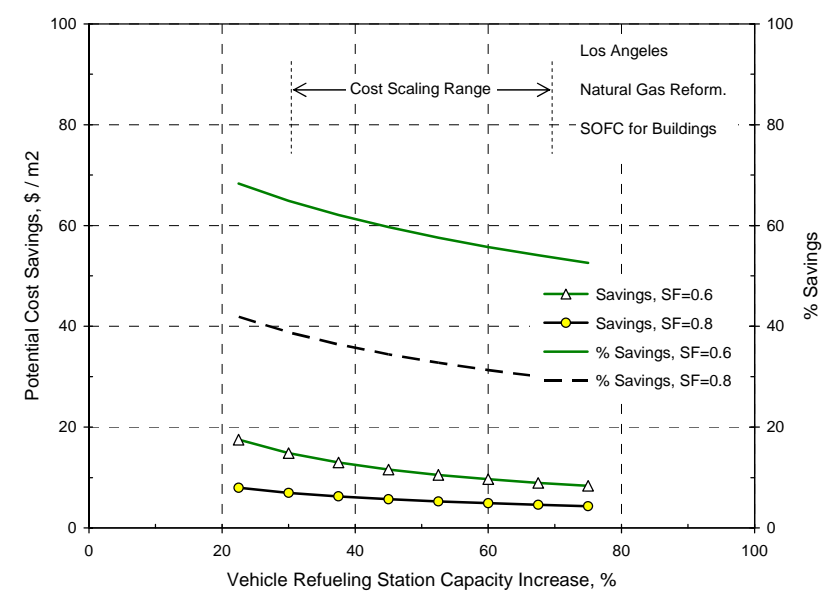

Figure 12. Cost savings from Model II integration

\section{$4 \quad$ Summary and Conclusions}

In this study, the energy consumption of various distributed systems, ranging from a basic configuration (FCDG) to more complex and advanced designs (FCDG-ADV and CHP) was examined for commercial building applications. The CHP configuration facilitated utilization of coincident heat and power output of the fuel cell subsystem to meet the building electrical and thermal loads, whereas the FCDG-ADV system applied the available heat to the steam methane reformation. These results in conjunction with the EIA data for commercial buildings facilitated assessment of the requirements for energy and water resources, assuming such technologies capture $20 \%$ of the national commercial market.

Integration of stationary and transportation applications was evaluated under two models for EIA-based commercialbuilding communities in various locations. In the first model (Model I), the hydrogen-production subsystem was slated to meet the design electrical loads of the buildings as the primary application. To support vehicle refueling as a secondary application, the hydrogen production unit was allowed to operate continuously for excess hydrogen production during the off-peak periods. Under the second model integration, Model II, the hydrogen production unit was primarily designated for the fueling station of the commercial community but was oversized to support the buildings' hydrogen requirements. For analysis of integrated stationary and transportation applications, the building types were limited to office, hospital, retail, and supermarket.

The primary energy reduction resulting from implementation of the basic hydrogen distributed system (FCDG) for buildings relative to the grid-dependent conventional systems was negligible, but the improvement with the GHG emissions was more appreciable. However, substantial improvements were realized with the more-advanced distributed systems-CHP and FCDG-ADV. The improvements were even greater for the latter system (FCDG-ADV) because (1) the heat utilization is internal and always coincident with the electricity output of the fuel cells and (2) the more-efficient SOFC is used. The increase in water consumption for the commercial buildings was estimated to range up to about $3 \%$ of the baseline amount.

It was demonstrated that, under Model I, a commercialbuilding community with a total floor area of $50,000 \mathrm{~m}^{2}$ can potentially meet the hydrogen demand of a $1,500-\mathrm{kg} /$ day FCV refueling station in Los Angeles. Due to their electrical load characteristics and dominance in the aggregate of the commercial buildings, office buildings contributed the most to the vehicle refueling capacity. The integration model eliminated the capital cost of installing a production system for the refueling station, potentially saving up to $\$ 1 \mathrm{M}$. In Model II, the refueling station capacity had to be doubled to support the same building community with $50,000-\mathrm{m}^{2}$ floor area. The economic potential of this model largely depends on the governing formulation of the economy of scale. Under a set of assumptions, an example showed a net cost reduction of about $\$ 0.5 \mathrm{M}$ when the $1,500-\mathrm{kg} /$ day refueling station is oversized by $60 \%$ to support a $30,000-\mathrm{m}^{2}$ building community.

In summary, application of hydrogen-based DG technologies in commercial buildings provides an opportunity to reduce primary energy consumption and GHG emissions. Integration of building and vehicle applications is also a promising concept that can lead to significant cost reduction by avoiding redundancy in hydrogen production installations. 


\section{ACKNOWLEGEMENTS}

Thanks are extended to Brent Griffith and Michael Deru of the National Renewable Energy Laboratory for providing the DOE benchmark load profiles for the selected commercial buildings.

\section{REFERENCES}

1. Greene, D. L. and Leiby, P. N. Integrated Analysis of Market Transformation Scenarios with HyTrans. Oak Ridge, TN: Oak Ridge National Laboratory. ORNL/TM2007/094, 2007.

2. U.S. Department of Energy. DOE Hydrogen Program, DOE H2A Analysis:

http://www.hydrogen.energy.gov/h2a_analysis.html.

3. Jalalzadeh-Azar, A. A. “A Parametric Analysis of a GridIndependent BCHP System: Focusing on Impact of Technological Advancements.” ASHRAE Transactions; Vol. 109(2), 2003. Atlanta: American Society of Heating, Refrigerating and Air-Conditioning Engineers, Inc.

4. Jalalzadeh-Azar, A. A. "A Comparison of Electrical- and Thermal-Load Following CHP Systems.” ASHRAE Transactions; Vol. 110(2), 2004; pp. 85-94. Atlanta: American Society of Heating, Refrigerating and AirConditioning Engineers, Inc.

5. Annual Energy Outlook 2008 with projections to 2030. DOE/EIA-0383 (2008).

6. Ellis, M. W. Fuel Cells for Building Applications. Atlanta: American Society of Heating, Refrigerating and AirConditioning Engineers, Inc. 2002.

7. Larminie, J., and A. Dicks. Fuel Cell Systems Explained. New York:John Wiley \& Sons, Ltd., 2000.

8. ASHRAE. 2008 ASHRAE Handboo-HVAC Systems and Equipment. Chapter 7. Atlanta: American Society of Heating, Refrigerating and Air-Conditioning Engineers, Inc.

9. Singhal. S. C., and K. Kendall. High Temperature Solid Oxide Fuel Cells. Oxford: Elsevier, 2003.

10. Deru, M., B. Griffith, N. Long, K. Benne, P. Torcellini, M. Halverson, D. Winiarski, J. Huang, and D. Crawley. "DOE Commercial Building Research Benchmark for Commercial Buildings.” Second Draft. Golden: National Renewable Energy Laboratory, 2008.
11. ASHRAE. ASHRAE Standard 90.1. Energy Standard for Buildings Except Low-Rise Residential Buildings.

Atlanta: American Society of Heating, Refrigerating and Air-Conditioning Engineers, Inc, 2004.

12. U.S. Department of Energy. Hydrogen Posture Plan. Washington, DC: DOE, December 2006: http://www.hydrogen.energy.gov/pdfs/hydrogen posture plan_dec06.pdf 